\title{
HOW POVERTY CONTRIBUTES TO ANTIMICROBIAL RESISTANCE
}

\author{
OVERUSE OF ANTIMICROBIAL DRUGS CREATES DANGEROUS RESISTANT \\ STRAINS OF MICROORGANISMS. YET IN SOME PLACES OF THE WORLD TODAY, \\ IT IS IMPOSSIBLE TO GET BY WITHOUT THEM. MEDICAL ANTHROPOLOGISTS \\ PROFESSOR CLARE CHANDLER AND SUSAN NAYIGA, OF THE LONDON SCHOOL \\ OF HYGIENE AND TROPICAL MEDICINE IN THE UK, STUDY HOW CONDITIONS \\ IN UGANDA FORCE RESIDENTS TO RELY ON ANTIBIOTICS ON A DAILY BASIS
}

\section{TALK LIKE A MEDICAL ANTHROPOLOGIST}

ANTIMICROBIAL DRUGS - drugs that

kill or suppress the growth of bacteria,

fungi, viruses and other microorganisms

in or on the human body, other animals

or plants

ANTIBIOTICS - a type of antimicrobial drug that kills or suppresses the growth of bacteria

\section{ANTIMICROBIAL RESISTANCE}

(AMR) - the ability of microorganisms to survive antimicrobial drugs due to evolutionary adaptations gained through repeated exposure to these drugs
MULTIMORBIDITY - multiple conditions that combine to create ill-health

\section{PARTICIPANT OBSERVATION - an} anthropological data collection method in which researchers join in with the activities of the people they are studying in order to observe through experience

\section{'ONE HEALTH' APPROACH - an} approach to health that combines diverse academic disciplines and considers animals, plants and the environment as well as humans
Antibiotics have transformed human life. Infections that once killed millions can now be cured by taking a few tablets. Yet this miraculous technology contains the seeds of its own destruction - the more we use antimicrobial drugs, the more microorganisms evolve, adapt and become resistant to them. Overuse of antimicrobials can breed dangerous 'superbugs' immune to any treatment. As a result, the United Nations considers antimicrobial resistance (AMR) to be a global high priority health issue and recommends reducing antimicrobial drug use.

But why do we overuse antibiotics, and why is it difficult to stop overusing them? With the Antimicrobials in Society (AMIS) project, Professor Clare Chandler and $\mathrm{PhD}$ researcher Susan Nayiga of the London School of Hygiene and Tropical Medicine are studying antibiotic use in rural and urban Uganda, highlighting the difficult choices local people face when it comes to health and work.

\section{THE PROBLEM OF \\ ANTIMICROBIAL OVERUSE}

Antimicrobial drugs have many important uses.

They cure and prevent infections in humans, animals and even crops. However, they have come to be used in cases beyond the strictly medically necessary. For example, people might use them to increase livestock productivity and as a quick fix to stop infections, rather than avoiding infections in the first place through better hygiene and sanitation infrastructure.

As human use of antimicrobials has increased, microorganisms have adapted and evolved to become resistant to these drugs. "It has been estimated that by 2050, 10 million lives a year could be lost due to drug-resistant infections," says Clare. The problem is a global one, as resistant strains bred in one small region can quickly travel around the world thanks to the interconnectedness of modern life and the world economy.

But reducing antimicrobial use is easier said than done. Many people have good reasons to rely on antibiotics in the short term, even if doing so increases the risk of superbugs in the long term. Medical anthropologists like Clare and Susan study how people interact with medicines. They use their research findings to help policy-makers develop policies that allow people to live with less reliance on antimicrobial drugs.

\section{ANTHROPOLOGICAL METHODS}

To study antibiotic use in rural and urban Uganda, Clare, Susan and the AMIS team used a method called 'participant observation'. They spent extended periods of time living with the communities they were studying, getting to know how things are done and what day-to-day life is like, immersing themselves in the local culture to understand the rules, the local community's idea of common sense, and how people respond to challenges within their cultural context.

They also used surveys and 'medicine bags' to discover how people interact with antibiotics. "Rather than asking 'do you use antibiotics?' which might be interpreted differently by different people, we showed people packets of locally available antibiotics," explains Susan. "We asked them to sort them into piles of medicines they recognised, medicines they used frequently and medicines they don't know. This helped us to understand the significance of medicines in people's lives." 
In addition to gathering data from communities, Susan and Clare put what they learnt into historical and political context. By examining past policy documents and evaluation reports, they were able to trace the influence of different local, national and international programmes and policies that had attempted to improve the health of particular populations. "Our analysis pulled together different threads of research, weaving together narratives that could describe and explain what we were seeing about antibiotic use in everyday lives," says Susan. This approach helped them understand why people use certain medicines and why they must rely on antibiotics instead of avoiding infections through hygiene and infrastructure.

\section{ISSUES IN RURAL AND URBAN UGANDAN COMMUNITIES}

Clare and Susan investigated antimicrobial use in two communities in Uganda. Nagongera is a rural village in Tororo District, while Namuwongo is an informal settlement (also called a 'slum') in Kampala, the capital of Uganda. In both communities, residents struggle with food poverty and access to clean water and public health infrastructure.

In Nagongera, water is available from wells and boreholes. The boreholes are a source of clean water, but the monthly access fee is more than many residents can afford. Instead, they must collect drinking water from wells that are contaminated by animals and potentially human waste. People in Namuwongo also lack reliable access to safe water, as water sources become contaminated during the rainy season.

In both communities, most households do not have access to a private latrine. Public toilets are available in the urban settlement of Namuwongo, but they are expensive to use and are closed at night. As a result, people are forced to use bushes, buckets and polythene bags as toilets. Residents are warned by public health campaigns to boil water before using it for cooking or drinking, but they do not always have the money for fuel or the time to boil water for multiple uses throughout the day.

Lack of clean water and sanitary facilities leads to diarrhoea and water-borne diseases. Although residents know why they are getting sick, they do not have the money to access facilities or the power to demand better infrastructure. They deal with poor health caused by lack of sanitation by taking small doses of antibiotics, sometimes forgoing food in favour of medicine. Residents must remain well enough to work or they will be unable to afford basics like food.

Susan recounts that "in Kampala diarrhoea was common and there was frequent use of antibiotics in anticipation of diarrhoea almost every week." This level of antimicrobial use contributes to AMR, but simply targeting antibiotic use reduction fails to address the root causes of overuse in these communities - poverty and lack of access to hygienic facilities. Policy-makers in local, national and international governments must address these infrastructural issues in order to reduce the risks from AMR.

\section{HOW LINKING POVERTY TO ANTIBIOTIC} USE IN UGANDA CAN HELP PREVENT

\section{GLOBAL SUPERBUGS}

Clare and Susan hope that their research will help global policy-makers address the causes of antimicrobial overuse. "We have promoted the concept that antibiotics are 'infrastructural', meaning that they are not only a part of the fabric of our health systems but also our societies," says Clare.

Awareness of why people overuse antibiotics highlights how merely restricting the use of these drugs is unlikely to be effective and will in fact harm struggling communities. Instead, providing access to clean water and public latrines in communities such as Nagongera and Namuwongo would make constant use of antibiotics

unnecessary, improve public health and quality of life in these communities and lower medical costs for residents. Not only that, but antibiotic use in Uganda is a global problem, not a local one, as drug-resistant microbes can quickly spread across the world. That makes poverty and lack of public health infrastructure in Ugandan slums a global problem, too.

Clare and Susan's research highlights the important contributions medical anthropology can make on many levels. Advances in medical technology are not enough to solve global public health issues because medicines are used by people and distributed by human political and

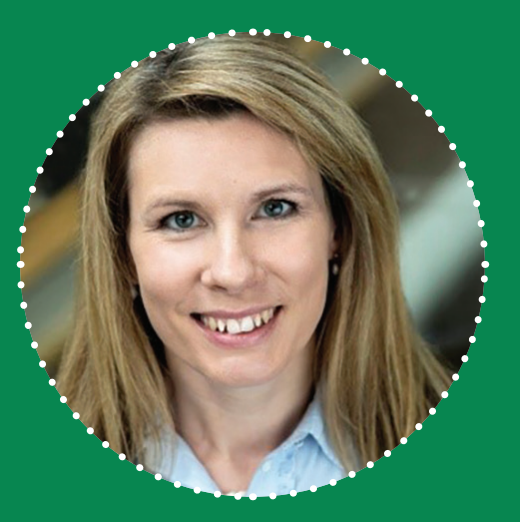

\section{PROFESSOR \\ CLARE CHANDLER}

Professor in Medical Anthropology London School of Hygiene and Tropical Medicine, UK

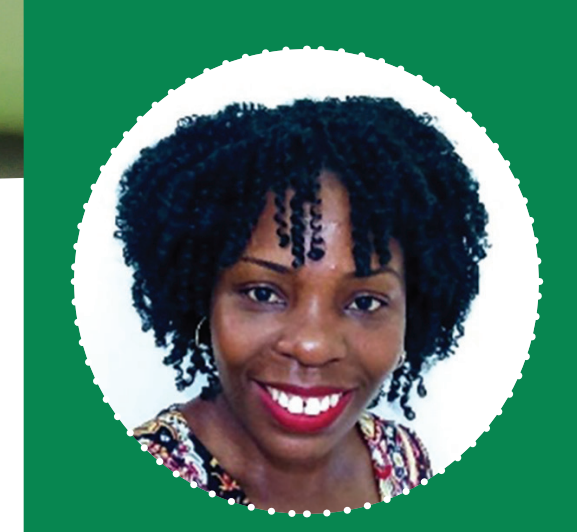

SUSAN NAYIGA

PhD student, London School of Hygiene and Tropical Medicine, UK

Researcher, Infectious Diseases Research Collaboration, Kampala, Uganda

\section{FIELD OF RESEARCH}

Medical Anthropology

\section{RESEARCH PROJECT}

Understanding how rural and urban communities in Uganda interact with antibiotics as a foundation for tackling

global antimicrobial resistance

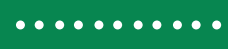

\section{FUNDERS}

ESRC, DHSC, GCRF

The Antimicrobials in Society (AMIS) grant was awarded by the Economic and Social Research Council (ESRC) on behalf of the Antimicrobial

Resistance Cross Council Initiative supported by the seven research councils of UK Research Innovation

(UKRI) in partnership with other funders [ES/ P008100/1]

economic systems. Medical anthropologists forge links between these different domains, allowing holistic solutions to be found in a 'one health' approach that help to solve pressing, real-world problems that affect us all. 
